\title{
Cigarette Design Features in Low-, Middle-, and High-Income Countries
}

\author{
Rosalie V. Caruso and Richard J. O'Connor \\ Department Of Health Behavior, Roswell Park Cancer Institute, Elm and Carlton Streets, Buffalo, NY 14263, USA \\ Correspondence should be addressed to Richard J. O’Connor, richard.oconnor@roswellpark.org
}

Received 30 November 2011; Accepted 23 February 2012

Academic Editor: Vaughan Rees

Copyright ( $) 2012$ R. V. Caruso and R. J. O'Connor. This is an open access article distributed under the Creative Commons Attribution License, which permits unrestricted use, distribution, and reproduction in any medium, provided the original work is properly cited.

\begin{abstract}
Previous studies have shown that country income grouping is correlated with cigarette engineering. Cigarettes $(N=111$ brands $)$ were purchased during 2008-2010 from 11 low-, middle-, and high-income countries to assess physical dimensions and an array of cigarette design features. Mean ventilation varied significantly across low- (7.5\%), middle- (15.3\%), and high-income (26.2\%) countries $(P \leq 0.001)$. Differences across income groups were also seen in cigarette length $(P=0.001)$, length of the tipping paper $(P=0.01)$, filter weight $(P=0.017)$, number of vent rows $(P=0.003)$, per-cigarette tobacco weight $(P=0.04)$, and paper porosity $(P=0.008)$. Stepwise linear regression showed ventilation and tobacco length as major predictors of ISO tar yields in lowincome countries $(P=0.909,0.047)$, while tipping paper $(P<0.001)$, filter length $(P<0.001)$, number of vent rows $(P=0.014)$, and per-cigarette weight $(P=0.015)$ were predictors of tar yields in middle-income countries. Ventilation $(P<0.001)$, number of vent rows $(P=0.009)$, per-cigarette weight $(P<0.001)$, and filter diameter $(P=0.004)$ predicted tar yields in high-income countries. Health officials must be cognizant of cigarette design issues to provide effective regulation of tobacco products.
\end{abstract}

\section{Introduction}

Tobacco production and consumption have risen dramatically in the developing world [1]. While smoking rates have declined in high-income countries, the public health burden of tobacco is shifting towards the developing world, where by 2030 more than $80 \%$ of the world's tobacco-related deaths will occur [2]. Coinciding with this shift to developing countries, health knowledge in these countries is increasing, albeit slowly in some places. While overall awareness of the health hazards of tobacco has improved in the last 15 years in China, it is still relatively poor. A household survey in China found that $81.8 \%$ of the population knew that smoking causes serious diseases, but fewer people realized the diseases that second hand smoke could present (64.3\%) [3]. Surveys in Ghana, however, show comparatively low smoking prevalence, high awareness of health risks, limited exposure to tobacco advertising, and frequent efforts by smokers to quit [4].

There is evidence that the multinational tobacco industry appears to be targeting Asia and Africa as growth regions [5]. The Framework Convention on Tobacco Control (FCTC), to which 174 countries are currently parties, contains a number of key demand-reducing strategies, such as tobacco taxation, education about health effects (including health warnings on packages), removal of misleading product descriptors, and support for cessation. FCTC also addresses the product itself, and the World Health Organization has received advice from its Study Group on Tobacco Product Regulation on tobacco product testing, reporting requirements, and possible emissions regulation $[6,7]$. The problems presented in developing countries will be multifold: to deal with the increasing public health burden, while implementing provisions of the FTC, including educating consumers about the harmful effects of cigarettes and regulating tobacco products.

Over the last five decades, as consumers have grown increasingly aware of the health hazards of smoking, tobacco companies have responded by designing and marketing seemingly lower tar and nicotine products that were positioned as less dangerous to health $[8,9]$. However, the testing methodology (e.g., International Organization for Standardization (ISO) and Federal Trade Commission (FTC)) that 
depicted lower tar and nicotine levels was unrepresentative of human smoking behavior, therefore, labels such as "low tar" often presented on packs or in advertising were meaningless to consumers as health indicators [10]. To market lower tar and nicotine cigarettes, tobacco manufacturers designed their cigarettes with characteristics such as cigarette filters on the ends of rods, which are able to reduce the machine yields of tar and nicotine by $40-50 \%$ [11]. Additionally, ventilation holes, which appear as a ring of holes in the cigarette paper surrounding the filter, dilute tobacco smoke coming from the mouth end when smoked by a machine and further reduce tar and nicotine emissions [11]. However, when smoked by consumers, vents can be blocked by fingers and lips, or their effect is reduced by greater puffing effort, such that smokers inhale more tar and nicotine than would be predicted by machine testing [12].

Broadly speaking, cigarette emissions are predictable to a large degree from design features [13-15]. In light of the shifting public health burden of tobacco use toward the developing world, Calafat et al. [16] showed that cigarette emissions and design varied widely across WHO regions, with cigarettes sold in the Eastern Mediterranean, South East Asia, and Western Pacific Regions having higher tar and lower ventilation than those sold in the African, American, or European regions. O'Connor et al. [17] examined the differences in cigarette design characteristics in high-, middle-, and low-income countries, with the general trend being that as country income group increased, cigarettes sold became more highly engineered and the nominal emission levels decreased [17]. All cigarettes from high-income countries had filters, compared with $95 \%$ of brands in middle-income and $86 \%$ of brands in low-income countries, and among these, the proportion having ventilated filters was $95 \%$ in high-income countries, $87.5 \%$ in middle income countries, and $44.4 \%$ in low-income countries. This current study seeks to replicate earlier findings relating cigarette design (and by extension, emissions) to country development grouping. More evidence from studies such as this one is needed in order for countries to implement meaningful regulation of tobacco, given the important links between cigarette design and smoke emissions [18].

\section{Methods}

Methods for this project mirror a previous study by O'Connor et al. [17], comparing cigarette design features of samples obtained from multiple low-, middle-, and highincome countries. Country income classification was based on the World Bank's Gross National Income per capita data [19]. The current study analyzed cigarettes from 11 countries $(N=111$ brands) purchased between 2008-2010 (see Table 1). Collaborators in each country purchased popular brands of cigarettes based on sales and prevalence data within each country. Nepal was the only country used in the current study that was also included in the previous study, but these were two separate purchases in two separate years. Packs were then shipped to Roswell Park Cancer Institute where the cigarettes were catalogued and stored at $-20^{\circ} \mathrm{C}$ until analysis. Before testing, cigarettes were conditioned for a minimum of
48 hours at $22 \pm 2.0^{\circ} \mathrm{C}$ and $60 \pm 2.0 \%$ relative humidity in an environmental chamber.

Product testing procedures followed those previously published by the same laboratory [14, 17]. After conditioning, five cigarettes were selected from each pack for physical analysis. Digital calipers were used to measure the length of the entire cigarette, the length and diameter of the tobacco rod, and the length and diameter of the filter. Filter and tobacco weight measurements were also taken using an analytical balance. The length of the tipping paper was then recorded and observed using a light box for the presence of vent holes. Tobacco moisture and dry weight were assessed using an HR83 Moisture Analyzer (MettlerToledo, Columbus, OH, USA). Filter ventilation and pressure drop were assessed using a KC-3 apparatus (Borgwaldt-KC, Richmond, VA). The level of porosity of the cigarette paper was measured using the vacuum method on a PPM1000M paper porosity device (Cerulean, Milton Keynes, UK). Tar and nicotine values were obtained from product packages where these were listed (Table 1).

Data analysis was completed using Statistical Package for the Social Sciences Version 16.0 (SPSS Inc., Chicago, IL, USA). Basic descriptive statistics and analysis of variance (ANOVA) were used to compare product design features by country income grouping. Discriminant function analysis was used to examine how combinations of design features distinguished low-, middle-, and high-income countries. Stepwise linear regression was used to assess the influence of design features on labeled tar and nicotine values. In these regression models, ventilation was forced into the model given extant literature on its major influence on ISO yields $[13,14,17]$, while other design features were entered using stepwise procedures $(P$-entry $=0.10, P$-removal $=0.15)$. Since tar and nicotine yields were provided on packs for only seven countries (see Table 1), the remaining countries were excluded from the regression analyses.

\section{Results}

Nearly all the cigarettes tested were filtered cigarettes; $100 \%$ of cigarettes from both high- and middle-income countries had filters while $89 \%$ of cigarettes from lowincome countries had filters. Among filtered cigarettes, only $16.0 \%$ in low-income countries had vent holes, compared to $65.5 \%$ in middle-income countries and $82.1 \%$ in highincome countries.

ANOVA analyses (Table 2) revealed basic differences in physical cigarette parameters by income groups in terms of: cigarette length $(P=0.001)$, length of the tipping paper $(P=$ $0.010)$, filter weight $(P=0.017)$, number of vent rows $(P=$ $0.003)$, per-cigarette tobacco weight $(P=0.040)$, ventilation $(P<0.001)$, and paper porosities $(P=0.008)$. The average percentage of cigarette ventilation differed significantly across income groups, with means of $7.49 \%, 15.34 \%$, and $26.21 \%$ for low-, middle-, and high-income groups, respectively, $(P<0.001)$. Rod diameter, filter diameter, tobacco length, and filter length were not shown to have significant differences by income groups. 
TABLE 1: Summary of countries, income groupings and brands studied.

\begin{tabular}{|c|c|c|c|c|c|}
\hline & Income group & Number of brands & Year pack was collected & Primary manufacturer & T \& N label on pack \\
\hline Bangladesh & Low & 5 & 2009 & British American Tobacco & No \\
\hline Ghana & Low & 7 & 2008 & British American Tobacco & Yes \\
\hline Nepal & Low & 16 & 2009 & Other & No \\
\hline Argentina & Middle & 10 & 2008 & Philip Morris & Some packs \\
\hline Malaysia & Middle & 13 & 2008 & British American Tobacco & Yes \\
\hline Nigeria & Middle & 14 & 2008 & British American Tobacco & Yes \\
\hline Thailand & Middle & 10 & 2008 & Thailand tobacco Monopoly & No \\
\hline Uruguay & Middle & 8 & 2010 & Other & No \\
\hline Canada & High & 7 & 2009 & British American Tobacco & Yes \\
\hline Taiwan & High & 11 & 2008 & Taiwan Tobacco and Liquor Corporation & Some packs \\
\hline UK & High & 10 & 2010 & Imperial Tobacco & Yes \\
\hline
\end{tabular}

TABLE 2: ANOVA, basic differences in physical parameters by income group.

\begin{tabular}{|c|c|c|c|c|c|c|c|}
\hline & Income group & Mean & Standard error & Minimum & Maximum & ANOVA & $P$ \\
\hline \multirow[t]{3}{*}{ Cigarette length } & Low & 79.45 & 1.24 & 66.57 & 84.16 & $F(2,108)=7.010$ & 0.001 \\
\hline & Middle & 82.77 & 0.34 & 78.61 & 93.87 & & \\
\hline & High & 83.80 & 1.04 & 71.79 & 99.08 & & \\
\hline \multirow[t]{3}{*}{ Rod diameter } & Low & 7.59 & 0.02 & 7.34 & 7.91 & $F(2,108)=0.079$ & 0.924 \\
\hline & Middle & 7.56 & 0.02 & 6.84 & 8.02 & & \\
\hline & High & 7.54 & 0.17 & 2.88 & 8.02 & & \\
\hline \multirow[t]{3}{*}{ Filter diameter } & Low & 7.58 & 0.02 & 7.20 & 7.77 & $F(2,108)=0.326$ & 0.723 \\
\hline & Middle & 7.60 & 0.02 & 6.81 & 7.85 & & \\
\hline & High & 7.50 & 0.18 & 2.55 & 7.82 & & \\
\hline \multirow[t]{3}{*}{ Tobacco length } & Low & 61.51 & 0.56 & 56.96 & 68.58 & $F(2,108)=0.845$ & 0.432 \\
\hline & Middle & 60.46 & 0.49 & 54.15 & 70.27 & & \\
\hline & High & 60.40 & 0.88 & 50.21 & 72.46 & & \\
\hline \multirow[t]{3}{*}{ Length of tipping paper } & Low & 25.70 & 0.76 & 18.39 & 32.65 & $F(2,105)=4.805$ & 0.010 \\
\hline & Middle & 27.98 & 0.48 & 15.32 & 36.40 & & \\
\hline & High & 28.93 & 0.87 & 18.94 & 38.30 & & \\
\hline \multirow[t]{3}{*}{ Filter length } & Low & 19.92 & 0.90 & 8.94 & 27.23 & $F(2,97)=2.552$ & 0.083 \\
\hline & Middle & 22.89 & 0.88 & 11.04 & 63.26 & & \\
\hline & High & 21.44 & 0.71 & 14.94 & 26.95 & & \\
\hline \multirow[t]{3}{*}{ Filter weight } & Low & 0.1029 & 0.0055 & 0.0458 & 0.1547 & $F(2,97)=4.263$ & 0.017 \\
\hline & Middle & 0.1178 & 0.0028 & 0.0600 & 0.1556 & & \\
\hline & High & 0.1172 & 0.0037 & 0.0895 & 0.1585 & & \\
\hline \multirow[t]{3}{*}{ Number of vent rows } & Low & 0.33 & 0.19 & 0.00 & 4.00 & $F(2,93)=6.226$ & 0.003 \\
\hline & Middle & 1.00 & 0.15 & 0.00 & 4.00 & & \\
\hline & High & 1.46 & 0.30 & 0.00 & 6.00 & & \\
\hline \multirow[t]{3}{*}{ Per-cigarette tobacco weight } & Low & 0.6928 & 0.0075 & 0.62 & 0.77 & $F(2,108)=3.324$ & 0.040 \\
\hline & Middle & 0.6581 & 0.0116 & 0.52 & 1.16 & & \\
\hline & High & 0.6486 & 0.0099 & 0.55 & 0.75 & & \\
\hline \multirow[t]{3}{*}{ Ventilation (\%) } & Low & 7.49 & 2.3595 & 0.00 & 42.22 & $F(2,105)=2.299$ & $<0.001$ \\
\hline & Middle & 15.34 & 1.6746 & 0.00 & 39.54 & & \\
\hline & High & 26.21 & 3.3641 & 0.76 & 68.20 & & \\
\hline \multirow[t]{3}{*}{ Paper porosity } & Low & 35.01 & 3.16 & 15.74 & 80.05 & $F(2,106)=5.18$ & 0.008 \\
\hline & Middle & 44.09 & 2.40 & 15.88 & 81.57 & & \\
\hline & High & 48.47 & 2.21 & 31.42 & 72.41 & & \\
\hline
\end{tabular}


A discriminant function analysis was used to examine how linear combinations of the panel of design features distinguished among low-, middle-, and high-income countries. Two functions were derived, accounting for $71.4 \%$ and $28.6 \%$ of variance, respectively. The first function $\left[X^{2}(22)=\right.$ 45.6, $P<0.002$ ] maximally separated the high-income group from low and middle, while the second function $\left[X^{2}(11)=\right.$ $14.1, P=0.167$ ] separated low- and middle-income groups but did not achieve statistical significance. Examination of the structure matrix suggested that ventilation, paper porosity, cigarette length, and rod diameter distinguished high from the remaining income group brands. Analysis of classification statistics showed that the discriminant functions correctly classified $56.3 \%$ of cases, ranging from $72.2 \%$ of the high-income brands to $43.5 \%$ of the middleincome brands and $69.9 \%$ of the low-income brands.

Stepwise linear regressions were done for all cigarettes with tar and nicotine values recorded on the pack. Percigarette weight, tipping paper, filter diameter, tobacco length, and paper porosity were all associated independently with tar yields, after ventilation was forced into the model (Adjusted $R$ square $=0.852$, see Table 3 ). For nicotine, ventilation, tipping paper, filter weight, and filter length were the variables predicting nicotine yields (Adjusted $R$ square $=$ 0.774 ; see Table 4 ). When stratified by income group, regression analyses found that a number of design features contributed independently to tar yields in high-income group countries, including ventilation $(P<0.001)$, tipping paper $(P=0.015)$, number of vent rows $(P=0.009)$, percigarette weight $(P<0.001)$, cigarette length $(P=0.055)$, and filter diameter $(P=0.004)$ (Table 3$)$. Middle-income countries had five variables accounting for differences in tar: ventilation, tipping paper length, filter length, number of vent rows in the tipping paper, per-cigarette weight, and cigarette length. In low-income countries ventilation and tobacco length primarily accounted for differences in tar. Ventilation was not statistically significant in both low- and middle-income countries (see Table 3 ).

When examining correlates of nicotine yield stratified by income group, we found a broadly similar pattern of results (Table 4). In all cases, ventilation and per-cigarette weight had the strongest independent associations with nicotine yield. Other contributors did differ across income groups: filter weight for the low-income $(P=0.078)$, tipping paper length $(P<0.001)$ and filter length $(P<0.001)$ for middleincome countries, and tobacco length for the high-income group countries $(P=0.046$; see Table 4$)$.

\section{Discussion}

This study largely replicates an earlier study [17] on the differences in cigarette characteristics between high-, middle-, and low-income countries. As expected, brands in higher income countries were engineered with filters and ventilation more commonly and at higher levels than in lower income countries. Ventilation is the main factor in the differences in tar and nicotine levels among cigarettes [13-15], and a majority of cigarettes in higher income countries employed ventilation to affect tar and nicotine. The main features that distinguished the high-income group brands from the lower income group brands were ventilation, paper porosity, cigarette length, and rod diameter, features which dilute the smoke and/or alter the amount of tobacco available for burning.

Patterns in variability in tar across products, by income group, were slightly different than for nicotine. While middle- and low-income countries shared ventilation and tobacco length accounting for most of the variability in tar across their cigarette products, in high-income countries a wider array of design features appeared to have independent influences on tar yields. The added length of the tipping paper is particularly interesting, as it sequesters otherwise smokeable tobacco from burning in a machine test, hence lowering yields [20]. In some countries, maximum tar levels, as measured by standardized smoking machines, have been set, such at the "10-1-10" upper limits for tar, nicotine, and carbon monoxide in the EU [21]. Consumers typically believe products with lower levels to be "healthier", even though the primary way those numbers are achieved is primarily through increased ventilation. The problem arises in that consumers can directly manipulate how much tar and nicotine they obtain from their cigarettes by blocking the vent holes in the filter or indirectly by taking larger puffs, which ventilation facilitates [11]. In either case, consumers receive more tar and nicotine than stated on the product while believing they have reduced their risks. Given the past history of light and mild cigarettes in developed countries, health officials in developing countries need to be cognizant of these design alterations that can contribute to seemingly "healthier" (i.e., reduced machine-measured tar and nicotine) products introduced into their markets in the coming years.

Parties to the World Health Organization Framework Convention on Tobacco Control (WHO FCTC) should see this study as further reason to consider cigarette design feature reporting when proposing measures in their countries that regulate the contents and emission of tobacco products (Article 9) and tobacco product disclosures by manufacturers (Article 10) [18]. As noted at COP-4, "Collecting data on product characteristics, such as cigarette design features, would help Parties improve their understanding of the impact these characteristics have on smoke emission levels, properly interpret measurements obtained and, more importantly, keep abreast of any changes to cigarette design features" [18]. In order to have effective product regulation, it is essential that governmental authorities have accurate information about the composition of those products to understand how manufacturers are complying with regulations [18].

A strength of the current study is its consistency with prior findings of statistically significant differences in cigarette design between high-, middle-, and low-income countries, even though completely different sets of cigarettes were tested from different high-, middle-, and low-income countries. The replication of the study further validates the differences in cigarette design between country income groups. At the same time, this study also shared the limitations of the first study [13], that is, the selected brands 
TABLE 3: Design features associated with ISO tar yields across all brands (a) and stratified by country income group (b).

(a) Overall

\begin{tabular}{|c|c|c|c|c|}
\hline $\begin{array}{l}\text { Final adjusted } \\
R \text {-square value }\end{array}$ & & Model & $\begin{array}{l}\text { Standardized } \\
\text { coefficients }\end{array}$ & Sig. \\
\hline \multirow{6}{*}{0.852} & & Vent & -0.722 & $<0.001$ \\
\hline & & Per-cig weight & 0.475 & $<0.001$ \\
\hline & & Tipping & -0.344 & $<0.001$ \\
\hline & & Filter diameter & 0.233 & 0.004 \\
\hline & & Tobacco length & -0.244 & 0.017 \\
\hline & & Paper porosity & -0.150 & 0.070 \\
\hline \multicolumn{5}{|c|}{ (b) Stratified by income group } \\
\hline & $\begin{array}{l}\text { Final adjusted } \\
R \text {-square value }\end{array}$ & Model & $\begin{array}{c}\text { Standardized } \\
\text { coefficients }\end{array}$ & Sig. \\
\hline \multirow{2}{*}{ Low } & \multirow{2}{*}{0.561} & Vent & -0.037 & 0.909 \\
\hline & & Tobacco length & -0.857 & 0.047 \\
\hline \multirow{6}{*}{ Middle } & \multirow{6}{*}{0.894} & Vent & 0.055 & 0.795 \\
\hline & & Tipping & -2.139 & $<0.001$ \\
\hline & & Filter length & 2.212 & $<0.001$ \\
\hline & & Number of rows & -0.547 & 0.014 \\
\hline & & Per-cigarette weight & 0.620 & 0.015 \\
\hline & & Cigarette length & -0.391 & 0.072 \\
\hline \multirow{6}{*}{ High } & \multirow{6}{*}{0.956} & Vent & -0.897 & $<0.001$ \\
\hline & & Tipping & -0.308 & 0.015 \\
\hline & & Number of rows & 0.266 & 0.009 \\
\hline & & Per-cigarette weight & 0.522 & $<0.001$ \\
\hline & & Cigarette length & -0.204 & 0.055 \\
\hline & & Filter diameter & 0.282 & 0.004 \\
\hline
\end{tabular}

TABLE 4: Design features associated with ISO nicotine yields across all brands (a) and stratified by country income group (b).

(a) Overall

\begin{tabular}{|c|c|c|c|c|}
\hline $\begin{array}{l}\text { Final adjusted } \\
R \text {-square value }\end{array}$ & & Model & $\begin{array}{l}\text { Standardized } \\
\text { coefficients }\end{array}$ & Sig. \\
\hline \multirow{4}{*}{0.774} & & Vent & -0.568 & $<0.001$ \\
\hline & & Tipping & -0.752 & $<0.001$ \\
\hline & & Filter weight & 0.937 & $<0.001$ \\
\hline & & Filter length & -0.447 & 0.059 \\
\hline \multicolumn{5}{|c|}{ (b) Stratified by income group } \\
\hline & $\begin{array}{l}\text { Final adjusted } \\
R \text {-square value }\end{array}$ & Model & $\begin{array}{c}\text { Standardized } \\
\text { coefficients }\end{array}$ & Sig. \\
\hline \multirow{3}{*}{ Low } & \multirow{3}{*}{0.860} & Vent & -0.191 & 0.385 \\
\hline & & Per-cigarette weight & 1.372 & 0.013 \\
\hline & & Filter weight & -0.627 & 0.078 \\
\hline \multirow{4}{*}{ Middle } & \multirow{4}{*}{0.915} & Vent & -0.430 & $<0.001$ \\
\hline & & Per-cigarette weight & 0.200 & 0.033 \\
\hline & & Tipping & -2.310 & $<0.001$ \\
\hline & & Filter length & 2.063 & $<0.001$ \\
\hline \multirow{3}{*}{ High } & \multirow{3}{*}{0.710} & Vent & -0.637 & $<0.001$ \\
\hline & & Per-cigarette weight & 0.537 & 0.003 \\
\hline & & Tobacco length & -0.333 & 0.046 \\
\hline
\end{tabular}


may not be fully representative of the market within each country. In addition to this, only brands from three lowincome countries were tested in this study. Future research on this topic should incorporate more design data from lower income countries. Also, the lower income countries chosen may not be completely representative of all cigarette design from lower income markets around the world.

As expected with our hypothesis, the current study shows how different cigarette design characteristics are among high-, middle-, and low-income countries. Smokers in higher income countries have been misled with cigarettes that appear to be less hazardous and have highly engineered cigarette design; lower income countries could avert these same mistakes by immediately establishing ways to regulate product ingredients and design. Public health officials need scientific evidence to better understand cigarette design and function.

\section{Conflict of Interests}

R. J. O'Connor has served as a consultant to the World Health Organization and the US Food and Drug Administration with respect to tobacco product regulation.

\section{Acknowledgment}

This work was supported by a grant from the National Cancer Institute (P01CA138389).

\section{References}

[1] R. M. Davis, M. Wakefield, A. Amos, and P. C. Gupta, "The hitchhiker's guide to tobacco control: a global assessment of harms, remedies, and controversies," Annual Review of Public Health, vol. 28, pp. 171-194, 2007.

[2] World Health Organization, WHO Report on the global tobacco epidemic, 2008-the MPOWER package, http://www .who.int/tobacco/mpower/2008/en/index.html.

[3] Y. Yang, J. J. Wang, C. X. Wang, Q. Li, and G. H. Yang, "Awareness of tobacco-related health hazards among adults in china," Biomedical and Environmental Sciences, vol. 23, no. 6, pp. 437-444, 2010.

[4] E. Owusu-Dabo, S. Lewis, A. McNeill, A. Gilmore, and J. Britton, "Support for smoke-free policy, and awareness of tobacco health effects and use of smoking cessation therapy in a developing country," Bmc Public Health, vol. 11, aricle 572, 2011.

[5] D. Doku, "The tobacco industry tactics-a challenge for tobacco control in low and middle income countries," African Health Sciences, vol. 10, no. 2, pp. 201-203, 2010.

[6] WHO Study Group on Tobacco Product Regulation, Guiding Principles for the Development of Tobacco Product Research and Testing Capacity and Proposed Protocols for the Initiation of Tobacco Product Testing: Recommendation 6, WHO, Geneva, Switzerland, 2004.

[7] WHO Study Group on Tobacco Product Regulation, "The scientific basis of tobacco product regulation: second report of a WHO study group," Tech. Rep. series no. 951, WHO, Geneva, Switzerland, 2008.

[8] B. Harris, "The intractable cigarette 'filter problem,'” Tobacco Control, vol. 20, pp. i10-16, 2011.
[9] R. W. Pollay and T. Dewhirst, "The dark side of marketing seemingly "light" cigarettes: successful images and failed fact," Tobacco Control, vol. 11, supplement 1, pp. i18-i31, 2002.

[10] D. Hammond, F. Wiebel, L. T. Kozlowski et al., "Revising the machine smoking regime for cigarette emissions: implications for tobacco control policy," Tobacco Control, vol. 16, no. 1, pp. 8-14, 2007.

[11] L. T. Kozlowski and R. J. O'Connor, "Cigarette filter ventilation is a defective design because of misleading taste, bigger puffs, and blocked vents," Tobacco Control, vol. 11, no. 1, pp. i40-i50, 2002.

[12] D. Hammond, N. E. Collishaw, and C. Callard, "Secret science: tobacco industry research on smoking behaviour and cigarette toxicity," The Lancet, vol. 367, no. 9512, pp. 781-787, 2006.

[13] L. T. Kozlowski, N. Y. Mehta, C. T. Sweeney et al., "Filter ventilation and nicotine content of tobacco in cigarettes from canada, the united kingdom, and the united states," Tobacco Control, vol. 7, no. 4, pp. 369-375, 1998.

[14] R. J. O'Connor, D. Hammond, A. McNeill et al., "How do different cigarette design features influence the standard tar yields of popular cigarette brands sold in different countries?” Tobacco Control, vol. 17, no. 1, pp. i1-i5, 2008.

[15] W. E. Stephens, "Dependence of tar, nicotine and carbon monoxide yields on physical parameters: implications for exposure, emissions control and monitoring," Tobacco Control, vol. 16, no. 3, pp. 170-176, 2007.

[16] A. M. Calafat, G. M. Polzin, J. Saylor, P. Richter, D. L. Ashley, and C. H. Watson, "Determination of tar, nicotine, and carbon monoxide yields in the mainstream smoke of selected international cigarettes," Tobacco Control, vol. 13, no. 1, pp. 45-51, 2004.

[17] R. J. O’Connor, K. J. Wilkins, R. V. Caruso, K. M. Cummings, and L. T. Kozlowski, "Cigarette characteristic and emission variations across high-, middle- and low-income countries," Public Health, vol. 124, no. 12, pp. 667-674, 2010.

[18] WHO FCTC/COP/4/6 Rev.1. 18 November 2010. Draft guidelines for the implementation of Articles 9 and 10 of the WHO Framework Convention on Tobacco Control.

[19] The World Bank, 2012, http://data.worldbank.org/about/ country-classifications/world-bank-atlas-method.

[20] N. E. Grunberg, D. E. Morse, V. A. Maycock, and L. T. Kozlowski, "Changes in overwrap and butt length of american filter cigarettes. an influence on reported tar yields," New York State Journal of Medicine, vol. 85, no. 7, pp. 310-312, 1985.

[21] R. J. O’Connor, K. M. Cummings, G. A. Giovino, A. McNeill, and L. T. Kozlowski, "How did uk cigarette makers reduce tar to $10 \mathrm{mg}$ or less?" British Medical Journal, vol. 332, no. 7536, article 302, 2006. 


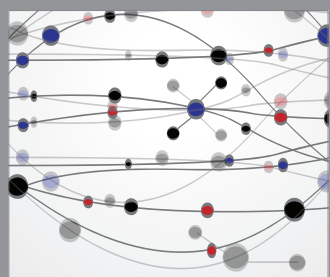

The Scientific World Journal
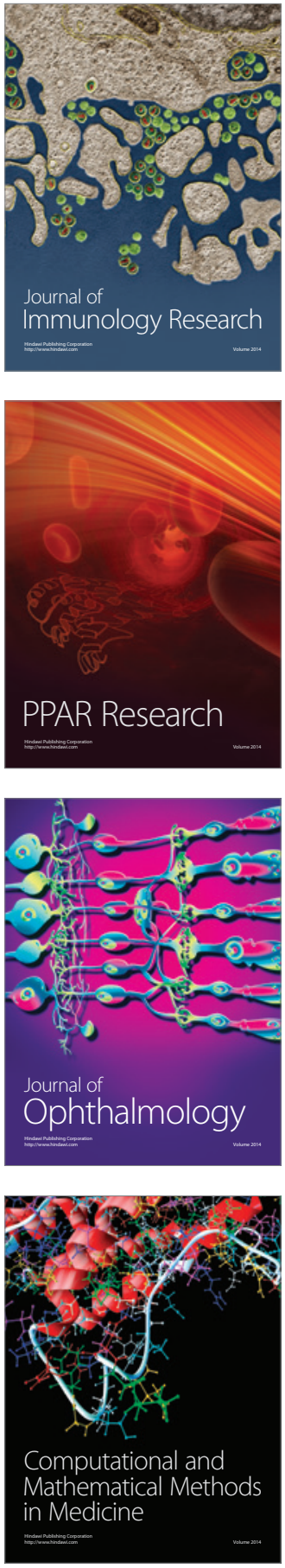

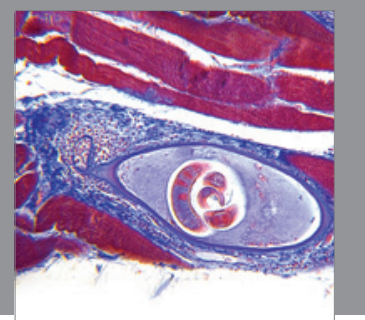

Gastroenterology

Research and Practice
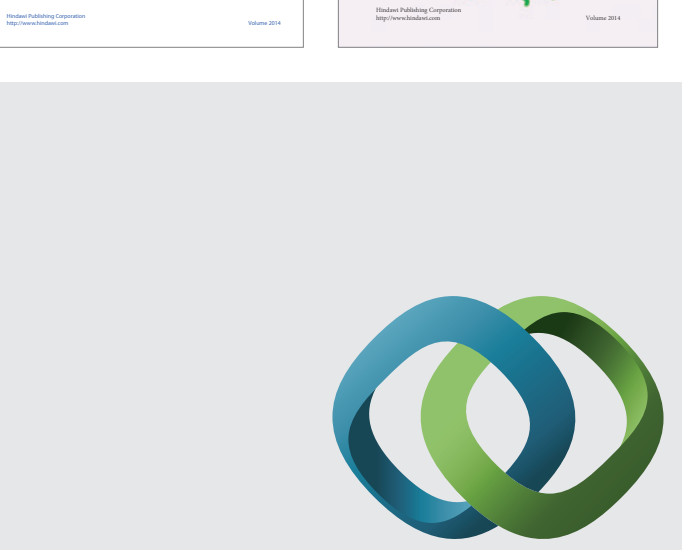

\section{Hindawi}

Submit your manuscripts at

http://www.hindawi.com
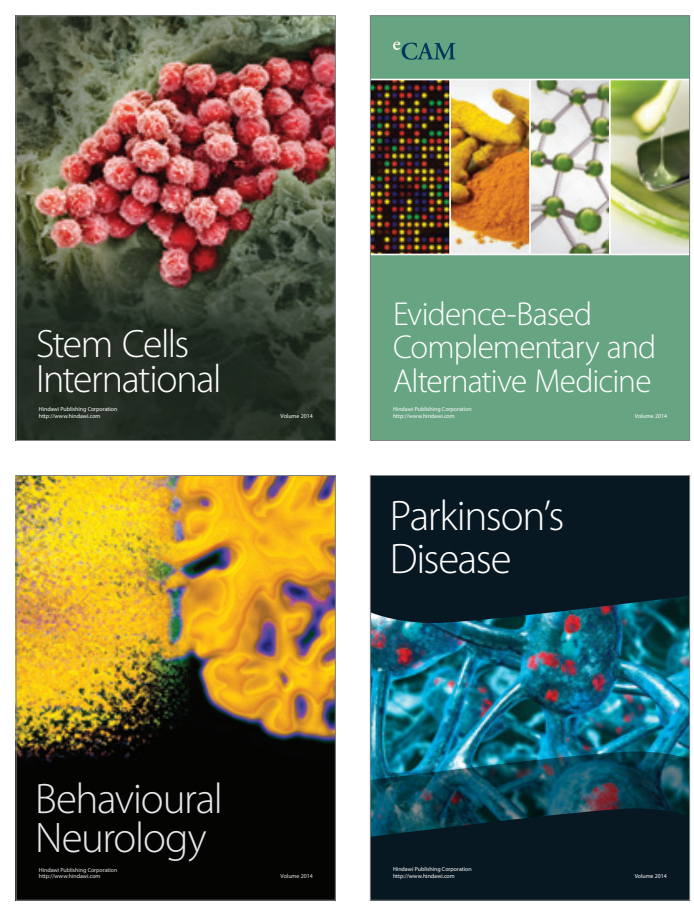

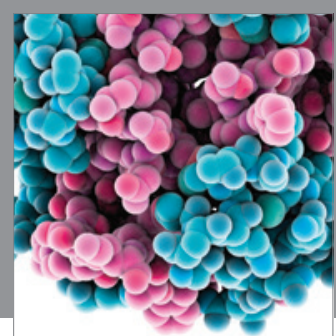

Journal of
Diabetes Research

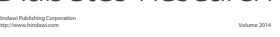

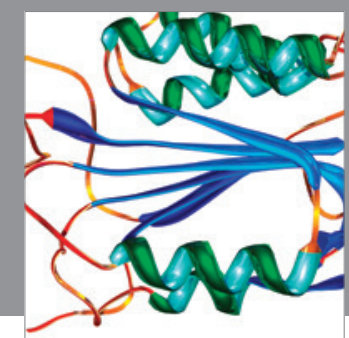

Disease Markers
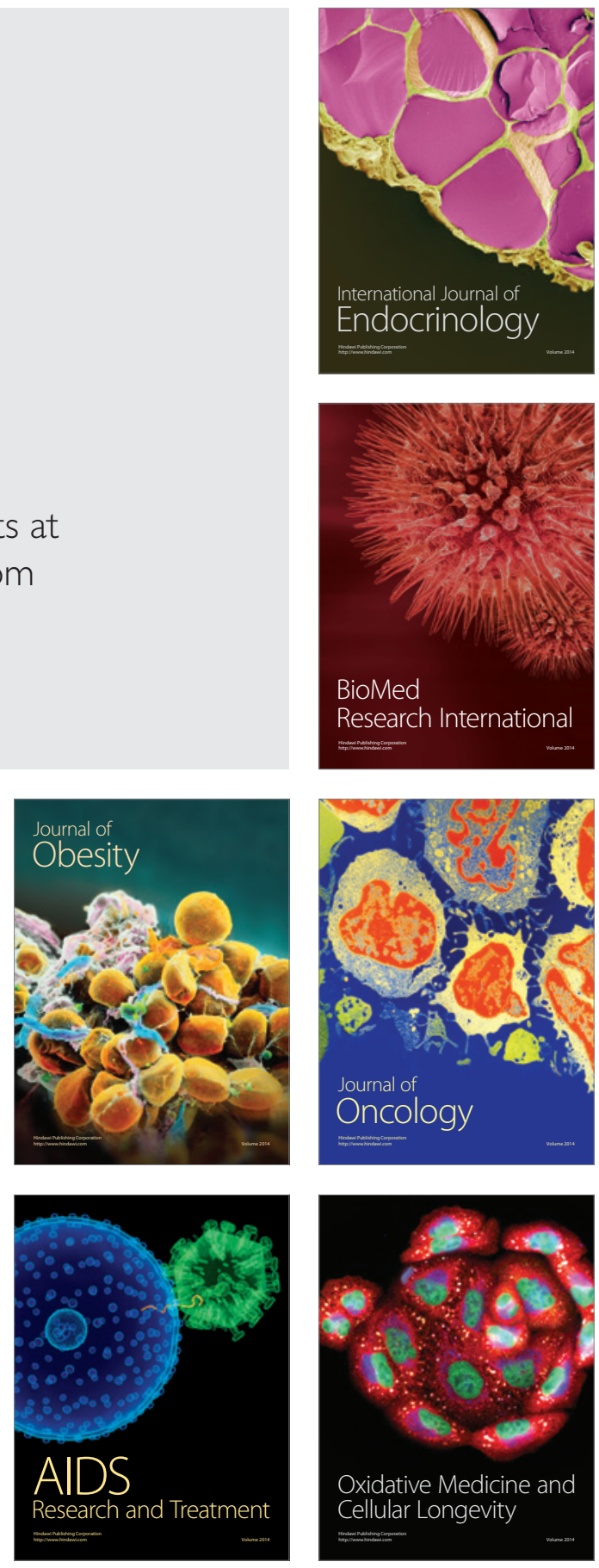